\title{
Adult teratoid Wilms' tumor: A case report of rare variant with predominant neuroepithelium
}

\author{
Amira Kamal El-Hawary ${ }^{1}$, Khaled Refaat Zalata ${ }^{1}$, Mahmoud Abdo El-Baz ${ }^{1}$, Huda Refaei ${ }^{2}$, Hassan \\ Abol Enein ${ }^{3}$ \\ 1. Pathology department, Faculty of medicine, Mansoura University, Mansoura, Egypt. 2. Radiology department, Urology \\ and Nephrology Center, Mansoura University, Mansoura, Egypt. 3. Urology department, Urology and Nephrology Center, \\ Mansoura University, Mansoura, Egypt.
}

Correspondence: Amira Kamal El-Hawary. Address: Pathology department, Faculty of medicine, Mansoura University, Mansoura, Egypt. E-mail: amira960@hotmail.com

Accepted: April 9, 2014

Online Published: April 15, 2014

DOI : $10.5430 /$ crcp.v1n2p42

URL: http://dx.doi.org/10.5430/crcp.v1n2p42

\section{Abstract}

Teratoid Wilms' tumor (WT) is a rare variant of nephroblastoma which had been only reported in pediatric patients. Herein, we report a 32-years-old female patient with teratoid WT with predominant heterologous neuroepithelial component of the right kidney. Histologically, the tumor showed the typical histological features of a teratoid WT formed of triphasic pattern of blastema, epithelium and stroma with heterologous elements which comprised more than $50 \%$ of the tumor area. The heterologous elements were mainly composed of neuroepithelial tissue including ganglion cells, differentiating neuroblasts, true and pseudorosettes, ganglioneuromatous differentiation, schwannianstroma, abundant neuropils admixed with mature types of epithelium and rhabdomyoblasts. This was the second reported case of adult teratoid WT with extensive neuroepithelial differentiation.

\section{Key words}

Adult, Teratoid Wilms’ tumor, Neuroepithelial differentiation

\section{Introduction}

Wilms' tumor (WT) is the most common abdominal tumor in children. It represented only $0.5 \%$ of all renal neoplasms in adults ${ }^{[1]}$. Up to date, about 300 well-documented cases of adult WT have been reported in the literature ${ }^{[2]}$. Teratoid WT is a rare variant of nephroblastoma in which heterologous tissue predominates including squamous or mucinous epithelium, smooth muscle, adipose tissue, cartilage, and osteoid and neurogenic tissue ${ }^{[3]}$. Fewer than 30 cases of teratoid WT have been reported until date ${ }^{[4]}$. This variant has been reported exclusively in pediatric patient ${ }^{[5]}$. Herein, we report a 32-year old patient with rare variant of teratoid WT with predominant neuroepitheliumof the right kidney.

\section{Case presentation}

A 32-year-old female presented with a two-month history of right lion pain. Abdominal examination revealed solid hypochondrial and lumber mass. Laboratory investigations revealed no abnormalities. Multidetector computed tomography scan revealed large soft tissue mass with heterogenous density nearly replacing the right kidney sparing the 
peripheral lower pole (see Figure 1A). The axial diameter was $(10 \mathrm{~cm} \times 11.6 \mathrm{~cm})$. After IV contrast administration, it showed very mild degree of enhancement (see Figure 1B).The mass extended to the perirenal space and right renal vein (see Figure 1C). There were multiple regional amulgamated lymphadenopathy encasing the aorta and IVC. The other kidney showed no abnormalities. Further evaluation by bone scan did not demonstrate any evidence of metastases. The patient was managed by right nephrorectomy and lymphadenectomy.

Macroscopically, the resected right kidney was measured $14 \mathrm{~cm} \times 10 \mathrm{~cm} \times 10 \mathrm{~cm}$ (see Figure 1D). There was a mass measuring $12 \mathrm{~cm} \times 10 \mathrm{~cm} \times 10 \mathrm{~cm}$ nearly replacing the whole kidney leaving peripheral rim of renal tissue with extension into the renal vein. The mass was well-circumscribed with a fleshy consistency, grey-tan color with yellowish areas of necrosis. The two lymph nodes were enlarged. One was measured $8 \mathrm{~cm} \times 4 \mathrm{~cm} \times 3 \mathrm{~cm}$ and the other was $6 \mathrm{~cm} \times 4 \mathrm{~cm} \times$ $2 \mathrm{~cm}$. The cut surface was similar to the cut surface of the mass. The right adrenal gland showed grayish white nodule which was measured $0.5 \mathrm{~cm} \times 0.5 \mathrm{~cm}$.

Histologically, the tumor showed the typical histological findings of a teratoid WT formed of triphasic pattern of blastema, epithelium (see Figure 2A), which showed positive staining for cytokeratin (see Figure 2B), and large areas of stroma. The blastemal cells were arranged in diffuse pattern and cellular nodules in loose fibromyxoidstroma. The blastema cells showed focal nuclear staining for WT-1. More than 50\% of the tumor areas were composed of stroma with heterologous elements composed of neural tissue, mature epithelium and skeletal muscle. The heterologous neural tissue were composed of abundant neuropils (see Figure 2C) which were positive for glial fibribillary acidic protein (GFAP) (see Figure 2D), ganglion-neuromatous differentiation (see Figure 3A), ganglion-neuroblastomous differentiation (see Figure 3B), true (see Figure 3C), pseudorosettes (see Figure 3D) and schwannian stroma. The ganglion cells and ganglioneuromatous differentiation showed positive cytoplasmic stain for synaptophysin (see Figure 4A). Schwannian stroma was positive for S-100 protein (see Figure 4B). The heterologous epithelia were composed of small nests of squamous (see Figure 4C) which were positive for cytokeratin (see Figure 4D). The renal vein was occluded by malignant thrombus. There was metastasis in the suprarenal gland and the lymph nodes. There were no anaplastic components. So, the final diagnosis of this case was stage III adult teratoid WT.

Figure 1. CT, MRI and gross picture of adult teratoidWilms' tumor
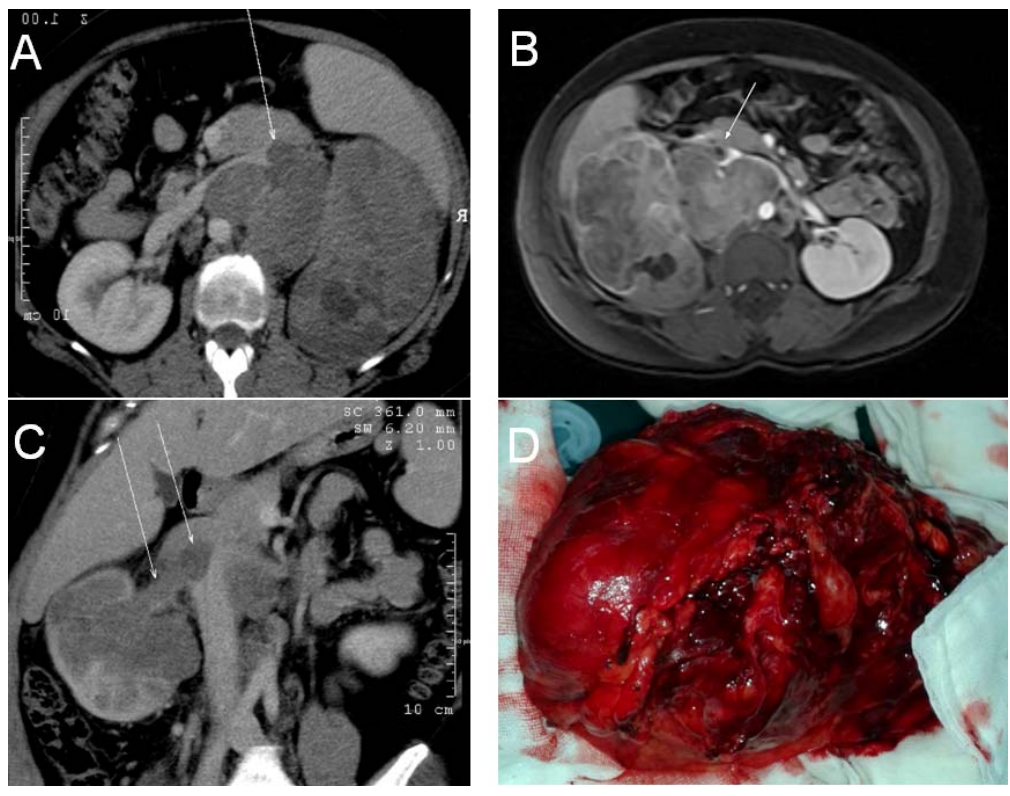

As shown in Figure 1, (A) and (B) axial \& coronal enhanced CT shows heterogeneous pattern with tumor extension to the renal vein. (C) MRI (SGRsequence with contrast) showed tongue-like projection of the tumor to IVC. (D). the gross picture of the resected right kidney measured $14 \mathrm{~cm} \times 10 \mathrm{~cm} \times 10 \mathrm{~cm}$. 
Figure 2. Histopathological features of adult teratoid Wilms' tumour
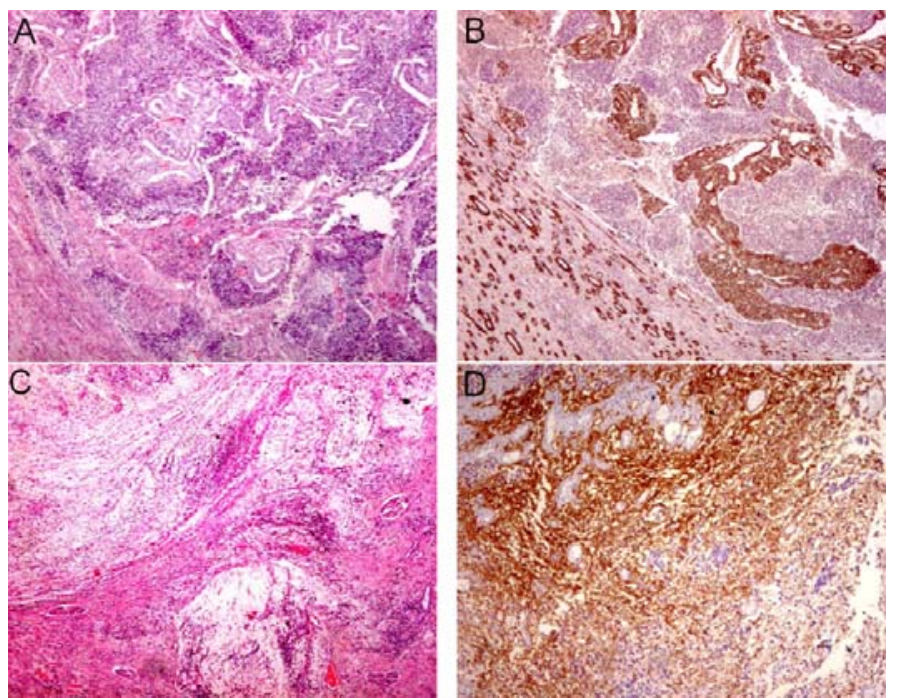

As shown in Figure 2, A. The triphasic histological'features of Wilms' tumor showed condensation of the blastema around the epithelial tubules $(\mathrm{H} \& \mathrm{E} \times 40)$. B. The epithelial elements were highlighted by positive staining for cytokeratin $\mathrm{C}$. The stromal components were formed mainly of neuroepithelial tissue rich in neuropils (H\&E $\times 40)$. D. Neuropils showed positive staining for glial fibrillary acidic protein $(\mathrm{DAB} \times 100)$.

Figure 3. Heterologous neuroepithelial tissue of adult teratoid Wilms' tumor. A. ganglioneuromatous differentiation (H\&E $\times 200$ ), B. ganglioneuroma-blastomoutous differentiation $(H \& E \times 100)$, C. True rosettes $(H \& E \times 100)$ and D. Pseudo rosettes (H\&E $\times 200$ ).

Figure 4. Heterologous elements of adult teratoid Wilms' tumor
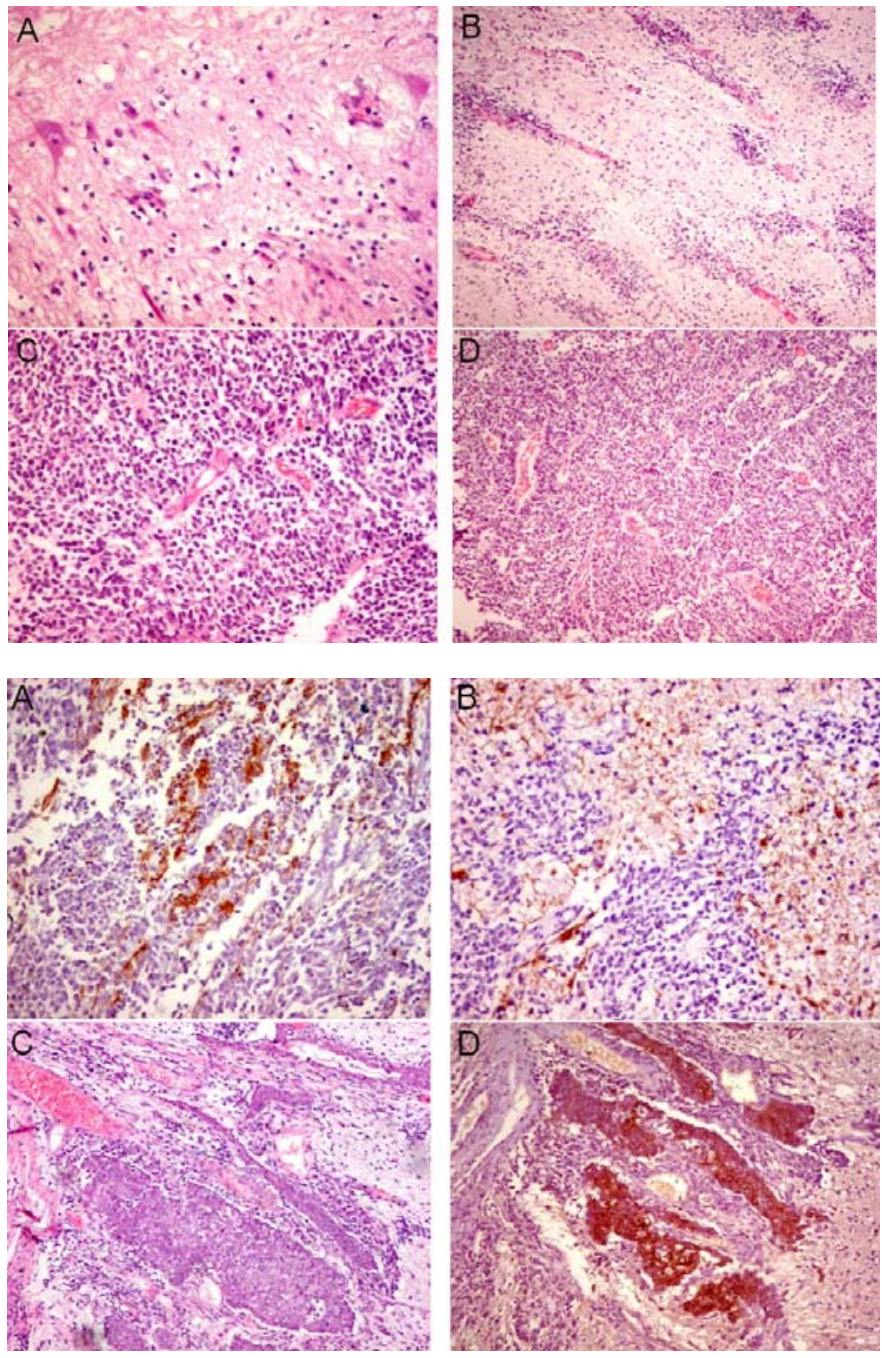
As shown in Figure 4, A. The neural cells of neuroepithelial tissue showed focal positive cytoplasmic staining for synaptophysin $(\mathrm{DAB} \times 200)$, B. Schwannian stroma are positive for S-100 protein $(\mathrm{DAB} \times 200)$, C. The heterologous epithelia composed of small nests of squamous epithelium (H\&E $\times 200)$, D. positive staining of the squamous epithelium for cytokeratin $(\mathrm{DAB} \times 100)$.

\section{Discussion}

Teratoid WT have been reported in the literature only in pediatric patients. Herein, we reported a case of adult teratoid WT. To our knowledge, this was the second reported case of adult teratoid WT with extensive neuroepithelial differentiation.

In 2009, Seo and his colleagues ${ }^{[5]}$ reported the first case of teratoid WT with prominent neuroepithelial differentiation occurring in a 50-year-old Korean man. They described the histopathological features of tumor as "having the typical triphasic patterns of WT with prominent heterologous components including rhabdomyoblasts, neuroepithelial tissue, fat, cartilage, and various types of mature epithelium”. In our case, the prominent heterologus element was the neuroepithelial elements, mature type of epithelium and rhabdomyoblasts.

Neural elements in WT were described originally by Harbitz, $1932{ }^{[6]}$ using silver-impregnation techniques. The author had identified only ganglion cells that might have been incorporated by the tumor. Llornbart-Bosch et al. ${ }^{[7]}$ thought that the ganglion cells in WTs may be due to stimulation of neural crest cells by neoplastic muscular cells,either striated or smooth type. In 1994, Murphey et al. ${ }^{[8]}$ proposed that heterologous differentiation of WTs may be due to aberrant differentiation of the metanephrogenic blastema. Hussong et al. ${ }^{[9]}$ reported four cases of WTs containing neural elements arising in a single familial aggregate. They proposed that this distinctive histologic type is related to the specific allele that confers WT predisposition in this family or is due to other genetic factors segregating in the family that modify the tumor histology.

Our case was the second in the literature to have advanced neuronal differentiation including ganglioneuromatous differentiation, true and pseudo rosettes, ganglion cells, schwannian stroma and abundant neuropils. In the previously reported cases of WT, The authors have described foci of peripheral nervous tissue (ganglion cells and Schwannian stroma) although these were not a prominent feature ${ }^{[10]}$. Kuo ${ }^{[11]}$ described glial cells and scattered ganglion cells in a WT, but did not confirm their characterization with more specific methods. Beckwith ${ }^{[12]}$ listed neuroglial epithelium among the various tissues observed in WTs in the American National Wilms' Tumor Study Pathology Center. Magee et al. ${ }^{[13]}$ found that four out of 48 cases of WT were positive for glial fibrillary acidic protein.

The differential diagnosis of WTs with neural differentiation includes malignant ectomesenchymoma (MEM), and primary renal teratoma and anaplastic sarcoma of the kidney (ASK) ${ }^{[5]}$. Characteristics consistent with WT, such as larger areas with blastema-like cells, epithelial differentiation as well as, positive immunohistochemical staining of WT-1 in the blastema-like foci were not histological features of these tumors. MEMs are characterized by both neuroectodermal (neuroblastoma, ganglioneuroblastoma, ganglioneurom, peripheral primitive neuroectodermal tumor) and mesenchymal components (usually rhabdomyosarcoma) ${ }^{[14]}$. Primary renal teratomas display unequivocal heterotopic organogenesis such as stratified squamous epithelium associated with skin adnexa, intestinal mucosal epithelium surrounded by smooth muscle bundles, and neuroglial tissue associated with choroid plexus epithelium ${ }^{[12]}$. ASK are composed of small primitive mesenchymal cells coexisting with a spindle cell component exhibiting anaplastic nuclear changes ${ }^{[15]}$. In summary, we have reported a case of a 32-year-old Egyptian female with a teratoid WT with predominant heterologous neuroepithelial differentiation. To our knowledge, this was the second reported case of adult teratoid WT with extensive neuroepithelial differentiation. It is an exceptional case in the adult population.

\section{Acknowledgement}

The authors thank Mr. Ebrahim Attia and Mr. Mohamed Kamal for their technical assistance. 


\section{References}

[1] Alapont JM, Pontones JL, Jimenez-Cruz JF. Wilm' tumour in adults. Int Braz J Urol. 2003; 29: 40-42. PMid: 15745466. http://dx.doi.org/10.1590/S1677-55382003000100008

[2] Terenziani M, Spreafico F, ColliniP, et al. Adult Wilms Tumor: A monoinstitutional experience and a review of the literature. Cancer. 2004; 101: 289-293. PMid: 15241825. http://dx.doi.org/10.1002/cncr.20387

[3] Sinha A, Phukan JP, Bandyopadhyay G, Mukherjee S. TeratoidWilms' tumor in a child: A report of a rare case. Int J App Basic Med Res. 2013; 3:72-74. PMid: 23776845. http://dx.doi.org/10.4103/2229-516X.112248

[4] Treetipsatit J, Raveesunthornkiet M, Ruangtrakool R, Sanpaki K, Thorner PS. Teratoid Wilms' tumor: Case report of a rare variant that can mimic aggressive biology during chemotherapy. J Pediatr Surg. 2011; 46: e1-6. PMid: 22152898. http://dx.doi.org/10.1016/j.jpedsurg.2011.09.049

[5] SeoJ, SuhYL, Choi HY. Adult teratoid Wilms' tumor with prominent neuroepithelial differentiation. Pathol Int. 2009 ; 59 (1): $44-48$. PMid: 19121091. http://dx.doi.org/10.1111/j.1440-1827.2008.02323.x

[6] Harbitz F: Sind einige der sogennanten 'adeno-sarcome' in dennieren in Wierlich Neuroblastome? Acta Pathol Microbiol Immunol Scand. 1932: 9: 199(Quoted from Magee et al, 1987).

[7] Llornbart-Bosch A, Peydro-Olaya A, Cerda-Nicolas M: Presence of ganglion cells in Wilms tumor: a review of the possible neuroepithelial origin of nephroblastoma. Histopathology. 1980; 4: 321-330. http://dx.doi.org/10.1111/j.1365-2559.1980.tb02925.x

[8] Murphy WM, Beckwith JB, Farrow GM. Tumors of the kidney. In: Atlas of Tumor Pathology, Third series, Fascicle II. Tumors of the Kidney, Bladder and Related Urinary Structures. Washington, DC: Armed Forces Institute of Pathology. 1994; 14-34. PMid: 10139776.

[9] Hussong JW, Erkins SP, Huff V, Atthewmcdonald M, Ysher TJ, Rucebeckwith JB, et al. Familial Wilms' tumor with neural elements: Characterization by histology, immunohistochemistry, and genetic analysis. Pediatr Dev Pathol. 2000; 3: 561-567. PMid: 11000334. http://dx.doi.org/10.1007/s100240010106

[10] Masson P. The role of neural crests in the embryonal adenosarcoma of the kidney. Am I Cancer. 1938: 33: 1-32. http://dx.doi.org/10.1158/ajc.1938.1a

[11] Kuo TT. Observation of nervous tissue in a Wilms' tumor: its histogenetic significance. Cancer. 1977; 39; $1105-1108$. http://dx.doi.org/10.1002/1097-0142(197703)39:3<1105::AID-CNCR2820390315>3.0.CO;2-Q

[12] Beckwith JB. Wilms' tumor and other renal tumors of childhood: a selective review from the National Wilms' Tumor Study Pathology Center. Hum Pathol. 1983: 14; 481-492. http://dx.doi.org/10.1016/S0046-8177(83)80003-3

[13] Magee F, Mah RG, Taylor GP, Dimmick JE. Neural differentiation in Wilms’ tumor. Hum Pathol. 1987; 18 : 33-37. http://dx.doi.org/10.1016/S0046-8177(87)80190-9

[14] Kösem M, Ýbiloðlu Y, Bakan V, Köseoðlu B. Ectomesenchymoma: case report and review of the literature. Turk J Pediatr. 2004; 46: 82-87. PMid: 15074381.

[15] Labanaris AP, Zugor V, Smiszek R, Nützel R, Kühn R. Anaplastic sarcoma of the kidney. The Scientific World Journal. 2009; 9: 97-101. PMid: 19219373. http://dx.doi.org/10.1100/tsw.2009.15 